\title{
Catalyst-free Hydrophosphinylation of Isocyanates and Isothiocyanates under Low-Added-Solvent Conditions
}

\author{
Cameron D. Huke, Laurence J. Taylor, Stephen P. Argent, and Deborah L. Kays*
}

Cite This: https://doi.org/10.1021/acssuschemeng.1c02907

Read Online

ACCESS |

Lull Metrics \& More

Article Recommendations

Supporting Information

ABSTRACT: A catalyst-free, low-solvent method for the hydrophosphinylation of isocyanates and isothiocyanates is reported. A range of phosphorus nucleophiles including secondary phosphine oxides $\mathrm{HP}(\mathrm{O}) \mathrm{R}_{2}\left(\mathrm{R}=\mathrm{Ph},{ }^{\mathrm{i}} \mathrm{Pr}\right)$, phosphites $\mathrm{HP}(\mathrm{O})(\mathrm{OR})_{2}(\mathrm{R}=\mathrm{Me}, \mathrm{Et})$, and methyl phenylphosphinate were tested. The procedure tolerated isocyanates and isothiocyanates featuring a wide range of substituents and, with use of 4 equiv of 2-methyltetrahydrofuran (2-MeTHF), solid substrates can be utilized. Twenty-five compounds were prepared with improved functional group tolerance compared to previous methods allowing access to new compounds (16 are novel). Facile scale up and simple reaction conditions make this a straightforward and practical methodology for obtaining phosphorus analogues of ureas and thioureas, which are challenging to synthesize by other methods.

KEYWORDS: hydrophosphinylation, hydrophosphonylation, atom-efficient, metal-free, heterocumulene, carboxamide, thiocarboxamide

\section{INTRODUCTION}

Organophosphorus compounds are of considerable importance due to their applications as medicines ${ }^{1,2}$ (antiviral and anticancer agents), agrochemicals ${ }^{3}$ (pesticides and herbicides), ligands in catalysis, ${ }^{4,5}$ and industrial additives ${ }^{6,7}$ (e.g., polymers and fire retardants). Classical syntheses of these compounds suffer from the use of stoichiometric additives, the need for protecting groups, and poor functional group tolerance. This has prompted research into the direct addition of $\mathrm{P}-\mathrm{H}$ (hydrophosphination) or $\mathrm{P}(\mathrm{O})-\mathrm{H}$ (hydrophosphinylation) bonds to $\mathrm{C}=\mathrm{X}(\mathrm{X}=\mathrm{C}, \mathrm{O}, \mathrm{N}, \mathrm{S})$ unsaturated bonds, which has the potential to be $100 \%$ atom-efficient. ${ }^{8}$

While alkene and alkyne substrates have been thoroughly explored, ${ }^{9-14}$ heterocumulenes are comparatively underutilized. There are several reports of catalytic hydrophosphination with heterocumulenes, ${ }^{15-28}$ and one catalyst-free example. ${ }^{29}$ Hydrophosphinylation of heterocumulenes is significantly rarer, with very few literature examples. ${ }^{30-33}$ This is despite hydrophosphinylation providing an atom economical route to air-stable phosphorus derivates of guanidines, ureas, and thioureas, which have potential applications as ligands, ${ }^{34-36}$ in the purification of lanthanide containing waste, ${ }^{37-39}$ in medicine, ${ }^{40,41}$ and as organic synthons. ${ }^{42}$

In previous work, the $\mathrm{Ca}(\mathrm{II})$-mediated hydrophosphinylation of isocyanates or isothiocyanates afforded the corresponding phosphinylcarboxamides or phosphinylthiocarboxamides (note these compounds are also known as carbamoylphosphine oxides or thiocarbamoylphosphine oxides, respectively) in moderate yields (Scheme 1a, top). ${ }^{30}$ However, the procedure required long reaction times $(12-48 \mathrm{~h})$ and high catalyst loadings for some aryl substrates (ca. $74 \mathrm{~mol} \%)$. A
Scheme 1. (a) Previous Catalytic Examples for the Hydrophosphinylation of Isocyanates and Isothiocyanates by Westerhausen et al. ${ }^{30}$ (top) and Panda et al. ${ }^{33}$ (bottom) and (b) Reactivity Presented in This Work ${ }^{a}$

a) Previous work
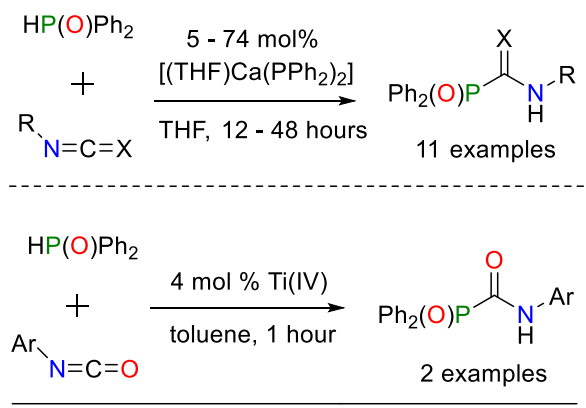

b) This work

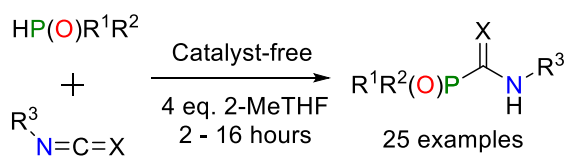

${ }^{a} \mathrm{X}=\mathrm{O}$ or $\mathrm{S} ; \mathrm{R}^{1}, \mathrm{R}^{2}=$ aryl, alkyl, alkoxy; $\mathrm{R}^{3}=$ aryl, alkyl.

Received: April 29, 2021

Revised: June 11, 2021 
Ti(IV) catalyst gave high yields for two aryl isocyanate substrates ${ }^{33}$ but showed no tolerance toward isothiocyanates (Scheme 1a, bottom). Additionally, both reactions suffer from the use of toxic chlorinated solvents in the workup.

Herein, we report the first catalyst-free, low-solvent hydrophosphinylation method that is applicable to a broad range of isocyanates and isothiocyanates. This method is highly atom economical, utilizes 2-MeTHF as a bioderived solvent, and uses no chlorinated solvents in the workup. The reactions proceed at room temperature or with mild heating $\left(60{ }^{\circ} \mathrm{C}\right)$ and do not require additional stoichiometric reagents. This method, therefore, aligns with several of the 12 Principles of Green Chemistry. In addition, similar or better yields are obtained compared to the previously reported catalytic methods. $^{30-33}$ The functional group tolerance and simple reaction conditions make this an excellent practical route to phosphinylcarboxamides and phosphinylthiocarboxamides. We also report 16 novel compounds prepared by this methodology (see ESI S3 for characterization data).

\section{RESULTS AND DISCUSSION}

Hydrophosphinylation of Isocyanates with Diphenylphosphine Oxide. Our initial experiments showed that the reaction of phenyl isocyanate (PhNCO) with diphenylphosphine oxide $\left(\mathrm{HP}(\mathrm{O}) \mathrm{Ph}_{2}\right)$ proceeded smoothly without additives (Table 1), despite previous literature suggesting

Table 1. Optimization of the Hydrophosphinylation of Phenyl Isocyanate under Catalyst-Free Conditions ${ }^{a}$

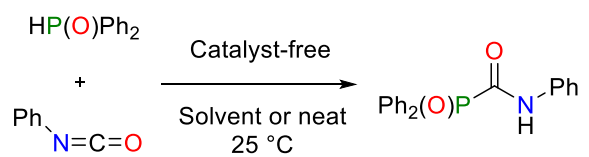

$\begin{array}{ccccc}\text { Entry } & \mathrm{HP}(\mathrm{O}) \mathrm{Ph}_{2}: \mathrm{Ph}-\mathrm{NCO} & \text { Solvent } & \text { Time }(\mathrm{h}) & \text { Conv. }(\%)^{b} \\ 1 & 1.0: 1.0 & \mathrm{C}_{6} \mathrm{D}_{6} & 8 & 70 \\ 2 & 1.0: 1.2 & \mathrm{C}_{6} \mathrm{D}_{6} & 8 & 73 \\ 3 & 1.0: 1.5 & \mathrm{C}_{6} \mathrm{D}_{6} & 8 & 73 \\ 4 & 1.0: 2.0 & \mathrm{C}_{6} \mathrm{D}_{6} & 8 & 71 \\ 5 & 1.5: 1.0 & \mathrm{C}_{6} \mathrm{D}_{6} & 8 & 71 \\ 6 & 1.0: 1.2 & \mathrm{THF} & 8 & 76 \\ 7 & 1.0: 1.2 & \mathrm{Neat} & 3 & 72 \\ 8 & 1.0: 1.2 & \mathrm{Neat}^{c} & 3 & 38 \\ 9 & 1.0: 1.2 & \mathrm{THF}^{d} & 3 & 80 \\ 10 & 1.0: 1.2 & 2-\mathrm{MeTHF}^{d} & 3 & 80\end{array}$

${ }^{a}$ Reaction conditions: 1.0 equiv $(0.10 \mathrm{mmol})$ of reactant, $0.5 \mathrm{~mL}$ of solvent, and $25{ }^{\circ} \mathrm{C}$ under a nitrogen atmosphere unless otherwise stated. ${ }^{b}$ Conversion determined by ${ }^{1} \mathrm{H}$ NMR spectroscopy using an internal standard (mesitylene, 1.0 equiv). ${ }^{c}$ Reaction performed in air. ${ }^{d}$ Approximately 4 equiv of solvent used.

that this reaction does not occur without a catalyst. ${ }^{30,31,43}$ The reaction could be performed in concentrated solutions (ca. 0.2 M, Table 1, entries 1-6) or neat (entry 7). Neat reactions were faster but gave variable yields, possibly due to issues with sample homogeneity. ${ }^{44}$ Reactions in air gave low conversions (entry 8). To allow for the use of solid substrates, a near-neat method using 4 equiv of THF (entry 9) or 2-MeTHF (entry 10) was employed.

A variety of functionalized isocyanates were also tested (Table 2). The reaction tolerated aromatic isocyanates with electron-donating and electron-withdrawing substituents (4$\mathrm{Me}, 2-\mathrm{F}, 4-\mathrm{Br}$, and 4-OMe substituted). All these reactions afforded pure product in reasonable yields $\left(62-82 \%\right.$ by ${ }^{1} \mathrm{H}$ NMR spectroscopy, 55-66\% isolated, Table 2). However, 4$\mathrm{NO}_{2} \mathrm{C}_{6} \mathrm{H}_{4} \mathrm{NCO}$ was not as well tolerated, proceeding with low conversions ( $49 \%$ by NMR spectroscopy) and significant byproduct formation. For a discussion of this byproduct and a proposed mechanism for its formation, see ESI S4.2 and S4.3. The reaction has been scaled up to gram scale $(1.55 \mathrm{~g}$ of $\left.\mathrm{HP}(\mathrm{O}) \mathrm{Ph}_{2}\right)$ using $\mathrm{PhNCO}$ without issue, with a higher isolated yield than the test-scale reaction $(74 \%$ vs $64 \%$; ESI S2.1.4).

High conversions were achieved with a range of primary and secondary alkyl isocyanates at $60{ }^{\circ} \mathrm{C}$ ( ${ }^{\mathrm{i}} \mathrm{Pr}, \mathrm{Et},{ }^{\mathrm{n}} \mathrm{Pr},{ }^{\mathrm{n}} \mathrm{Hex}, \mathrm{Cy}$; $82-91 \%$ by NMR spectroscopy, $65-82 \%$ isolated). The very bulky ${ }^{\mathrm{t}} \mathrm{BuNCO}$ required longer reaction times $(8 \mathrm{~h})$ to reach moderate conversions ( $61 \%$ by NMR spectroscopy, $48 \%$ isolated), and increasing the reaction temperature to $80{ }^{\circ} \mathrm{C}$ did not improve conversion. The chain length of primary isocyanates did not appear to affect conversion. The benzyl functionality was tolerated, giving $\mathbf{1 1}$ in $56 \%$ isolated yield, while the heterocyclic furfuryl isocyanate afforded $\mathbf{1 n}$ in $35 \%$ isolated yield. No uretdione $[-\mathrm{NRC}(\mathrm{O})-]_{2}$ (dimerization) or isocyanurate $[-\mathrm{NRC}(\mathrm{O})-]_{3}$ (cyclotrimerization) byproducts were detected, even with aryl isocyanates, for which some examples are known to dimerize at room temperature without a catalyst. ${ }^{45}$ Significantly, all products (except 1f) were purified by washing with small quantities of ethanol (ESI, S2.1.3).

These hydrophosphinylation reactions parallel recent work on the catalyst-free hydrophosphination of alkenes, alkynes, and iso(thio)cyanates. ${ }^{29,46,47}$ However, our methodology shows broader substrate scope than these reports and, crucially, does not require column chromatography for purification, leading to a significant reduction in waste compared to these processes.

Hydrophosphinylation of Isothiocyanates with Diphenylphosphine Oxide. Recently, $\mathrm{Li}$ et al. reported the hydrophosphinylation of PhNCS by $\mathrm{HP}(\mathrm{O}) \mathrm{Ph}_{2}$ to afford $\mathrm{Ph}_{2} \mathrm{P}(\mathrm{O}) \mathrm{C}(\mathrm{S}) \mathrm{NH}(\mathrm{Ph}){ }^{48}$ This reaction was carried out neat at $60{ }^{\circ} \mathrm{C}$, but we found that addition of 2-MeTHF (4 equiv) afforded the product $(\mathbf{2 a})$ in excellent yields (90\% isolated yield) and eliminated the need for heating (Table 2 ).

Subsequently, a range of aryl isothiocyanates featuring electron-donating and -withdrawing substituents (4-Me, 4-Cl, and 4-OMe substituted) were tested, with all giving the expected product in excellent isolated yields $(\mathbf{2} \mathbf{b}-\mathbf{2 d}, \mathbf{d}-\mathbf{9 0}-95 \%$, Table 2). Like 4- $\mathrm{NO}_{2} \mathrm{C}_{6} \mathrm{H}_{4} \mathrm{NCO}, 4-\mathrm{NO}_{2} \mathrm{C}_{6} \mathrm{H}_{4} \mathrm{NCS}$ gave low conversions with significant byproduct formation (ESI, S4.2 and S4.3), although a pure sample of the product (2e) was obtained (ESI, S2.1.3; 31\% isolated). Secondary alkyl isothiocyanates required heating $\left(60{ }^{\circ} \mathrm{C}, 6 \mathrm{~h}\right)$ for high conversions, although the yields are significantly lower than the corresponding alkyl isocyanates. The less bulky allyl isothiocyanate, by contrast, proceeded with near quantitative conversion ( $2 \mathrm{~h}, \mathbf{9 5 \%}$ by NMR spectroscopy).

Hydrophosphinylation and Hydrophosphonylation with Other $\mathrm{P}(\mathrm{O})-\mathrm{H}$ Nucleophiles. Since all previous reports of hydrophosphinylation of isocyanates and isothiocyanates were limited to secondary aryl phosphine oxides, ${ }^{30-33}$ we tested diisopropylphosphine oxide $\left(\mathrm{HP}(\mathrm{O})^{\mathrm{i}} \mathrm{Pr}_{2}\right)$ as a substrate (Table 3). Reactions with PhNCO (affording 3a) and ${ }^{\mathrm{i}} \mathrm{PrNCO}$ (affording 3c) proceeded at $60{ }^{\circ} \mathrm{C}$ with modest isolated yields (41\% and 61\% respectively, Table 3). Reaction with PhNCS at $60{ }^{\circ} \mathrm{C}$ afforded $3 \mathrm{~b}$ in very high isolated yield (95\%). However, 
Table 2. Hydrophosphinylation of Isocyanates and Isothiocyanates with Diphenylphosphine Oxide ${ }^{a}$

(a)

1a: $25{ }^{\circ} \mathrm{C}, 3 \mathrm{~h}, 64 \%(80 \%) \quad$ 1b: $25{ }^{\circ} \mathrm{C}, 3 \mathrm{~h}, 66 \%(82 \%) \quad$ 1c: $25^{\circ} \mathrm{C}, 4 \mathrm{~h}, 55 \%(62 \%)$ 1d: $25^{\circ} \mathrm{C}, 4 \mathrm{~h}, 61 \%(75 \%)$<smiles>COc1cc(NC(=O)[PH2+]C(=O)[OH+]c2ccccc2)cc(OC)c1</smiles>
1e: $25^{\circ} \mathrm{C}, 4 \mathrm{~h}, 63 \%(74 \%) \quad$ 1f: $25^{\circ} \mathrm{C}, 4 \mathrm{~h},(49 \%) \quad 1 \mathrm{~g}: 60^{\circ} \mathrm{C}, 6 \mathrm{~h}, 67 \%(84 \%) \quad$ hh: $60{ }^{\circ} \mathrm{C}, 8 \mathrm{~h}, 48 \%(61 \%)$<smiles>CCNC(=O)[OH+]c1ccccc1</smiles><smiles>CCCNC(=O)[OH+]c1ccccc1</smiles>

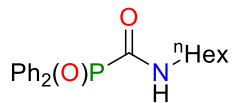<smiles>O=C(NCc1ccccc1)[OH+]c1ccccc1</smiles>

1i: $60{ }^{\circ} \mathrm{C}, 6 \mathrm{~h}, 71 \%(84 \%)$

1k: $60{ }^{\circ} \mathrm{C}, 6 \mathrm{~h}, 65 \%(82 \%)$

1I: $60{ }^{\circ} \mathrm{C}, 6 \mathrm{~h}, 56 \%(69 \%)$<smiles>O=C(NC1CCCCC1)POc1ccccc1</smiles><smiles>O=C(NCc1ccco1)[PH2+]c1ccccc1</smiles><smiles>S=C(Nc1ccccc1)[TeH+]c1ccccc1</smiles><smiles>Cc1ccc(NC(=S)[OH+]c2ccccc2)cc1</smiles>

1m: $60{ }^{\circ} \mathrm{C}, 6 \mathrm{~h}, 82 \%(91 \%) \quad$ 1n: $60{ }^{\circ} \mathrm{C}, 6 \mathrm{~h}, 35 \%(50 \%)$

2a: $25^{\circ} \mathrm{C}, 2 \mathrm{~h}, 90 \%(95 \%)$

2b: $25^{\circ} \mathrm{C}, 2 \mathrm{~h}, 95 \%(99 \%)$<smiles>S=C(Nc1ccc(Cl)cc1)[P-]c1ccccc1</smiles><smiles>COc1ccc(NC(=S)[OH+]c2ccccc2)cc1</smiles><smiles>O=[N+]([O-])c1ccc(NC(=S)[OH+]c2ccccc2)cc1</smiles><smiles>S=C(NC1CCCCC1)[TeH]c1ccccc1</smiles>

2c: $25^{\circ} \mathrm{C}, 2 \mathrm{~h}, 90 \%(94 \%) \quad 2 \mathrm{~d}: 25^{\circ} \mathrm{C}, 2 \mathrm{~h}, 92 \%(98 \%)$

2e: $60{ }^{\circ} \mathrm{C}, 6 \mathrm{~h}, 31 \%(50 \%) \quad 2 \mathrm{f}: 60^{\circ} \mathrm{C}, 6 \mathrm{~h}, 42 \%(57 \%)$<smiles>CC(C)NC(=S)[OH+]c1ccccc1</smiles><smiles>C=CCNC(=S)[OH+]c1ccccc1</smiles>

2g: $60{ }^{\circ} \mathrm{C}, 6 \mathrm{~h}, 40 \%$ (65\%)

2h: $60{ }^{\circ} \mathrm{C}, 4 \mathrm{~h}, 82 \%(95 \%)$

${ }^{a}$ Reaction stoichiometry: $\mathbf{1 a}, \mathbf{1 b}, \mathbf{1 d}, \mathbf{1 g}-\mathbf{1 m}$ isocyanate (1.2 equiv) and $\mathrm{HP}(\mathrm{O}) \mathrm{Ph}_{2}(1.0$ equiv); $\mathbf{1 c}, \mathbf{1 e}-\mathbf{1 f}, \mathbf{2 a}-\mathbf{2 h}$ iso(thio)cyanate (1.0 equiv) and $\mathrm{HP}(\mathrm{O}) \mathrm{Ph}_{2}$ (1.0 equiv), 1.0 equiv $=0.30 \mathrm{mmol}$. NMR spectroscopic yield (in brackets) determined by ${ }^{1} \mathrm{H}$ NMR spectroscopy using an internal standard (mesitylene, 1.0 equiv).

the reaction with ${ }^{\mathrm{i}} \mathrm{PrNCS}$ proceeded with low conversions (36\%), and the product (3d) was not obtained pure.

The methodology was then expanded to hydrophosphonylation, the addition of a $\mathrm{HP}(\mathrm{O})(\mathrm{OR})_{2}(\mathrm{R}=$ alkyl or aryl) unit across a double bond (Table 3). Kaboudin and Zahedi have previously described the catalytic hydrophosphonylation of isocyanates with $\mathrm{CaCl}_{2}$, which required chlorinated solvents and column chromatography in the workup. ${ }^{49}$ Initial reactions with $\mathrm{PhNCO}$ and $\mathrm{HP}(\mathrm{O})(\mathrm{OEt})_{2}$ in 2-MeTHF showed no conversion at $25{ }^{\circ} \mathrm{C}$ and $<5 \%$ conversion at $60{ }^{\circ} \mathrm{C}$. However, performing the reaction neat at $60{ }^{\circ} \mathrm{C}$ increased conversion to 87\% (ESI, S2.3.1). Purification of the phosphonyl carboxamide (4a) from residual $\mathrm{HP}(\mathrm{O})(\mathrm{OEt})_{2}$ by washing (ethanol) and recrystallization afforded $4 a$ in $\sim 87 \%$ purity (by ${ }^{31} \mathrm{P}$ NMR spectroscopy). Column chromatography (utilizing the method of Kaboudin and Zahedi) ${ }^{49}$ resulted, in our hands, in partial decomposition of the product. Attempts at vacuum distillation also decomposed 4a. Similar difficulties in removing residual $\mathrm{P}(\mathrm{V})$ starting material occurred with $\mathrm{HP}(\mathrm{O})(\mathrm{OMe})_{2}$ and $\mathrm{HP}(\mathrm{O}) \mathrm{Ph}(\mathrm{OMe})$, although products of $\geq 97 \%$ purity (by ${ }^{31} \mathrm{P}$ NMR spectroscopy) could be obtained in moderate yield in both cases (Table 3, $\mathbf{4 b}$ and $\mathbf{4 c}$, ESI S3.4). The use of less electrophilic substrates (PhNCS, ${ }^{\mathrm{i}} \mathrm{PrNCO},{ }^{\mathrm{i}} \mathrm{PrNCS}$ ) resulted in very low conversions $(<0.1-20 \%$, ESI S2.3.2).

Improvements and Considerations on the Sustainability of the Synthesis of Phosphinylcarboxamides. While isocyanates or isothiocyanates are generally toxic and potential irritants, ${ }^{50,51}$ it should be recognized that the addition of $\mathrm{HP}(\mathrm{O}) \mathrm{Ph}_{2}$ to isocyanates or isothiocyanates is the most atom efficient methodology for the synthesis of phosphinylcarboxamides or phosphinylthiocarboxamides, avoiding the use of stoichiometric reagents or low atom economic processes. ${ }^{52,53}$ Isocyanates can be generated in situ, ${ }^{54-58}$ but this uses additional stoichiometric reagents or metal catalysts to 
Table 3. Hydrophosphinylation and Hydrophosphonylation of Isocyanates and Isothiocyanates with $\left.\mathrm{HP}_{(\mathrm{O})}\right)^{\mathrm{i}} \mathrm{Pr}_{2}$, $\mathrm{HP}(\mathrm{O})(\mathrm{OEt})_{2}, \mathrm{HP}(\mathrm{O})(\mathrm{OMe})_{2}$, and $\mathrm{HP}(\mathrm{O}) \mathrm{Ph}(\mathrm{OMe})^{a, b, c}$

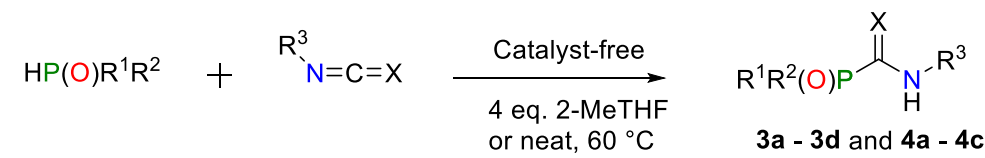

$$
\begin{aligned}
& { }_{{ }^{i} r_{2}(O) P}
\end{aligned}
$$

3a: $60{ }^{\circ} \mathrm{C}, 16 \mathrm{~h}, 41 \%(60 \%)$

3b: $60^{\circ} \mathrm{C}, 16 \mathrm{~h}, 99 \%(95 \%)$

3c: $60{ }^{\circ} \mathrm{C}, 16 \mathrm{~h}, 61 \%(80 \%)$<smiles>CC(C)=CPC(=S)NC(C)C</smiles>

3d: $60{ }^{\circ} \mathrm{C}, 16 \mathrm{~h},(36 \%)$<smiles>CCOC(=O)Nc1ccccc1</smiles>

4a: $60{ }^{\circ} \mathrm{C}, 16 \mathrm{~h},(87 \%)$<smiles>CO[PH2]C(=O)Nc1ccccc1</smiles>

4c: $60{ }^{\circ} \mathrm{C}, 16 \mathrm{~h}, 40 \%{ }^{\mathrm{d}}(62 \%)$<smiles>COC(=O)Nc1ccccc1</smiles>

4b: $60{ }^{\circ} \mathrm{C}, 16 \mathrm{~h}, 22 \%{ }^{\mathrm{d}}(48 \%)$

\footnotetext{
${ }^{a}$ Reaction stoichiometry: iso(thio)cyanate (1.0 equiv) and $\mathrm{HP}(\mathrm{O}) \mathrm{R}^{1} \mathrm{R}^{2}$ (1.0 equiv), 1.0 equiv $=0.105 \mathrm{mmol}(3 \mathrm{a}-\mathrm{c})$ or $0.232 \mathrm{mmol}(4 \mathrm{a}-\mathrm{c})$. ${ }^{b}$ Reaction performed in 4 equiv of 2 -MeTHF $(\mathbf{3 a}-\mathbf{d}, \mathbf{4 c})$ or neat $(\mathbf{4 a}, \mathbf{b}) .{ }^{c} \mathrm{NMR}$ spectroscopic yield (in brackets) determined by ${ }^{1} \mathrm{H}$ NMR spectroscopy using an internal standard (mesitylene, 1.0 equiv). ${ }^{d}$ Final isolated product $\geq 97 \%$ pure (by ${ }^{31} \mathrm{P}$ NMR spectroscopy).
}

activate the isocyanate precursors. It is worth noting that the majority of organophosphorus $\mathrm{P}(\mathrm{V})$ derivatives are originally derived from toxic and pyrophoric white phosphorus. However, there is intense interest in improving the sustainability of routes to organophosphorus $\mathrm{P}(\mathrm{V})$ derivatives (e.g., avoiding $\mathrm{P}_{4}$ ), which will only enhance the sustainability of our reported methodology. ${ }^{59-61}$ Our development of routes to lower toxicity $\mathrm{P}(\mathrm{V})$ species, such as phosphonate derivatives, also offers improvements over previous syntheses using $\mathrm{P}$ (III) derivatives.

In order to quantify the improvement in the sustainability of our synthetic methodology to phosphinylcarboxamides over the current catalytic methods, we have compared it to the Efactor values for hydrophosphinylation reactions of aryl isocyanates from the literature examples (see ESI, S5). The $\mathrm{Ca}$ (II) mediated reaction by Westerhausen et al. gives an Efactor of 142.5 , and the Ti(IV) mediated reaction by Panda et al. gives a value of 154.2 (some values for solvent purification are estimated as values are not given by the authors.). ${ }^{30,33}$ Comparatively, our work shows a significant improvement with an E-factor of 9.1. Additionally, our procedure eliminates the use of toxic dichloromethane for purification, instead utilizing ethanol and avoiding column chromatography. Moreover, our methodology avoids the use of catalysts entirely, whereas nearstoichiometric catalyst loading was required for some substrates in previous methodologies. ${ }^{30}$ Other substantial improvements can be seen in short reaction times for all substrates and easily scalable reactions. Overall, this is a significant improvement in sustainability for the synthesis of phosphinylcarboxamides, justifying the use of isocyanate and isothiocyanate substrates.

Mechanistic Proposal. To test for the formation of radicals, a radical inhibitor (1,4-cyclohexadiene or cumene) was added to the reaction of $\mathrm{HP}(\mathrm{O}) \mathrm{Ph}_{2}$ with $p$-tolyl isocyanate (ESI, S4.1). The reaction was not influenced by either radical inhibitor and the expected product was detected in high yield in both cases.

We propose a mechanism involving the equilibrium between $\mathrm{HP}(\mathrm{O}) \mathrm{R}_{2}$ and its $\mathrm{P}(\mathrm{III})-\mathrm{OH}$ tautomer. ${ }^{62-65}$ The isocyanate or isothiocyanate undergoes attack by the $\mathrm{P}(\mathrm{III})-\mathrm{OH}$ nucleophile, followed by a proton transfer to reform the $\mathrm{P}=$ O bond (ESI, S4.2). ${ }^{66}$ This mechanistic proposal is analogous to the initial steps of the mechanism proposed by $\mathrm{Li}$ and coworkers. $^{48}$

\section{CONCLUSIONS}

We have developed a catalyst-free methodology for the hydrophosphinylation of isocyanates and isothiocyanates by $\mathrm{HP}(\mathrm{O}) \mathrm{Ph}_{2}$ and $\mathrm{HP}(\mathrm{O})^{\mathrm{i}} \mathrm{Pr}_{2}$. These reactions can be performed neat, but the addition of 4 equiv of 2-MeTHF improves yields and allows for the use of solid substrates. This methodology has enabled the synthesis of 16 new compounds and substantially improved upon the limited substrate scope of the previous research. All but two of the 25 phosphinylcarboxamide and phosphinylthiocarboxamide products were readily purified by washing with ethanol. The protocol is practical and can be scaled up to gram scale with improved yields. Although attempts at hydrophosphonylation were less successful, it was possible to obtain products of high purity for the reactions of $\mathrm{HP}(\mathrm{O})(\mathrm{OMe})_{2}$ or $\mathrm{HP}(\mathrm{O}) \mathrm{Ph}(\mathrm{OMe})$ with $\mathrm{PhNCO}$.

\section{ASSOCIATED CONTENT}

\section{SI Supporting Information}

The Supporting Information is available free of charge at https://pubs.acs.org/doi/10.1021/acssuschemeng.1c02907. 
Full experimental details for the synthesis, characterization, and crystallographic data (PDF)

Crystallographic structures (CIF)

\section{AUTHOR INFORMATION}

\section{Corresponding Author}

Deborah L. Kays - School of Chemistry, University of Nottingham, Nottingham NG7 2RD, United Kingdom; (1) orcid.org/0000-0002-4616-6001;

Email: Deborah.Kays@nottingham.ac.uk

\section{Authors}

Cameron D. Huke - School of Chemistry, University of Nottingham, Nottingham NG7 2RD, United Kingdom

Laurence J. Taylor - School of Chemistry, University of Nottingham, Nottingham NG7 2RD, United Kingdom; (1) orcid.org/0000-0002-4948-4267

Stephen P. Argent - School of Chemistry, University of Nottingham, Nottingham NG7 2RD, United Kingdom

Complete contact information is available at: https://pubs.acs.org/10.1021/acssuschemeng.1c02907

\section{Notes}

The authors declare no competing financial interest.

\section{ACKNOWLEDGMENTS}

This work was supported by the Engineering and Physical Sciences Research Council [grant numbers EP/R004064/1, $\mathrm{EP} / \mathrm{L} 015633 / 1]$; and the University of Nottingham. We also thank the Mass Spectrometry Service and Dr. Tong Liu at the University of Nottingham for mass spectrometry and $\mathrm{CHN}$ measurements, respectively.

\section{REFERENCES}

(1) De Clercq, E. Antivirals: Past, Present and Future. Biochem. Pharmacol. 2013, 85 (6), 727-744.

(2) Demkowicz, S.; Rachon, J.; Daśko, M.; Kozak, W. Selected Organophosphorus Compounds with Biological Activity. Applications in Medicine. RSC Adv. 2016, 6 (9), 7101-7112.

(3) Singh, B. K.; Walker, A. Microbial Degradation of Organophosphorus Compounds. FEMS Microbiol. Rev. 2006, 30 (3), 428471.

(4) Bayardon, J.; Jugé, S. P-Chiral Ligands; Kamer, P. C. J., Van Leeuwen, P. W. N. M., Eds.; John Wiley \& Sons, Ltd: Chichester, UK, 2012 DOI: 10.1002/9781118299715.ch12.

(5) Allen, D. W. Phosphines and Related C-P Bonded Compounds; Allen, D. W., Tebby, J. C., Loakes, D., Eds.; The Royal Society of Chemistry: Cambridge, UK, 2016; Vol. 45 DOI: 10.1039/ 9781782626930-00001.

(6) Monge, S.; Canniccioni, B.; Graillot, A.; Robin, J. J. PhosphorusContaining Polymers: A Great Opportunity for the Biomedical Field. Biomacromolecules 2011, 12 (6), 1973-1982.

(7) Wendels, S.; Chavez, T.; Bonnet, M.; Salmeia, K. A.; Gaan, S. Recent Developments in Organophosphorus Flame Retardants Containing P-C Bond and Their Applications. Materials 2017, 10 (7), 784-815.

(8) (a) Wauters, I.; Debrouwer, W.; Stevens, C. V. Preparation of Phosphines through C-P Bond Formation. Beilstein J. Org. Chem. 2014, 10, 1064-1096. (b) Huke, C. D.; Kays, D. L. Hydrofunctionalization reactions of heterocumulenes: Formation of $\mathrm{C}-\mathrm{X}$ $(\mathrm{X}=\mathrm{B}, \mathrm{N}, \mathrm{O}, \mathrm{P}, \mathrm{S}$ and $\mathrm{Si}$ ) bonds by homogeneous metal catalysts. Adv. Organomet. Chem. 2021, 75, 1-54.

(9) Coudray, L.; Montchamp, J. L. Recent Developments in the Addition of Phosphinylidene-Containing Compounds to Unactivated Unsaturated Hydrocarbons: Phosphorus-Carbon Bond Formation by
Hydrophosphinylation and Related Processes. Eur. J. Org. Chem. 2008, 3601-3613.

(10) $\mathrm{Xu}, \mathrm{Q}$; Han, L. B. Metal-Catalyzed Additions of H-P(O) Bonds to Carbon-Carbon Unsaturated Bonds. J. Organomet. Chem. 2011, 696 (1), 130-140.

(11) Koshti, V.; Gaikwad, S.; Chikkali, S. H. Contemporary Avenues in Catalytic $\mathrm{P}-\mathrm{H}$ Bond Addition Reaction: A Case Study of Hydrophosphination. Coord. Chem. Rev. 2014, 265 (1), 52-73.

(12) Rodriguez-Ruiz, V.; Carlino, R.; Bezzenine-Lafollée, S.; Gil, R.; Prim, D.; Schulz, E.; Hannedouche, J. Recent Developments in Alkene Hydro-Functionalisation Promoted by Homogeneous Catalysts Based on Earth Abundant Elements: Formation of C-N, C-O and C-P Bond. Dalton Trans. 2015, 44 (27), 12029-12059.

(13) Bange, C. A.; Waterman, R. Challenges in Catalytic Hydrophosphination. Chem. - Eur. J. 2016, 22 (36), 12598-12605.

(14) Bezzenine-Lafollée, S.; Gil, R.; Prim, D.; Hannedouche, J. FirstRow Late Transition Metals for Catalytic Alkene Hydrofunctionalisation: Recent Advances in C-N, C-O and C-P Bond Formation. Molecules 2017, 22 (11), 1901-1929.

(15) Zhang, W. X.; Nishiura, M.; Hou, Z. Alkali-Metal-Catalyzed Addition of Primary and Secondary Phosphines to Carbodiimides. A General and Efficient Route to Substituted Phosphaguanidines. Chem. Commun. 2006, No. 36, 3812-3814.

(16) Zhang, W. X.; Nishiura, M.; Mashiko, T.; Hou, Z. HalfSandwich o-N,N-Dimethylaminobenzyl Complexes over the Full Size Range of Group 3 and Lanthanide Metals. Synthesis, Structural Characterization, and Catalysis of Phosphine P-H Bond Addition to Carbodiimides. Chem. - Eur. J. 2008, 14 (7), 2167-2179.

(17) Gu, X.; Zhang, L.; Zhu, X.; Wang, S.; Zhou, S.; Wei, Y.; Zhang, G.; Mu, X.; Huang, Z.; Hong, D.; Zhang, F. Synthesis of Bis(NHC)Based CNC-Pincer Rare-Earth-Metal Amido Complexes and Their Application for the Hydrophosphination of Heterocumulenes. Organometallics 2015, 34 (18), 4553-4559.

(18) Batrice, R. J.; Eisen, M. S. Catalytic Insertion of E-H Bonds (E $=\mathrm{C}, \mathrm{N}, \mathrm{P}, \mathrm{S})$ into Heterocumulenes by Amido-Actinide Complexes. Chem. Sci. 2016, 7 (2), 939-944.

(19) Sharpe, H. R.; Geer, A. M.; Lewis, W.; Blake, A. J.; Kays, D. L. Iron(II)-Catalyzed Hydrophosphination of Isocyanates. Angew. Chem., Int. Ed. 2017, 56 (17), 4845-4848.

(20) Zhang, Y.; Qu, L.; Wang, Y.; Yuan, D.; Yao, Y.; Shen, Q. Neutral and Cationic Zirconium Complexes Bearing Multidentate Aminophenolato Ligands for Hydrophosphination Reactions of Alkenes and Heterocumulenes. Inorg. Chem. 2018, 57 (1), 139-149.

(21) Crimmin, M. R.; Barrett, A. G. M.; Hill, M. S.; Hitchcock, P. B.; Procopiou, P. A. Heavier Group 2 Element Catalyzed Hydrophosphination of Carbodiimides. Organometallics 2008, 27 (4), 497499.

(22) Al-Shboul, T. M. A.; Volland, G.; Görls, H.; Westerhausen, M. [Bis(Tetrahydrofuran-O)-Bis(1,3-Dialkyl-2-Diphenylphosphanyl-1, 3Diazaallyl)Calcium] - Synthesis and Crystal Structures of Calcium Bis[Phospha(III)Guanidinates] and Investigations of Catalytic Activity. Z. Anorg. Allg. Chem. 2009, 635 (11), 1568-1572.

(23) Roering, A. J.; Leshinski, S. E.; Chan, S. M.; Shalumova, T.; MacMillan, S. N.; Tanski, J. M.; Waterman, R. Insertion Reactions and Catalytic Hydrophosphination by Triamidoamine-Supported Zirconium Complexes. Organometallics 2010, 29 (11), 2557-2565.

(24) Barrett, A. G. M.; Crimmin, M. R.; Hill, M. S.; Hitchcock, P. B.; Lomas, S. L.; Mahon, M. F.; Procopiou, P. A. Carbodiimide Insertion Reactions of Homoleptic Heavier Alkaline Earth Amides and Phosphides. Dalton. Trans. 2010, 39 (31), 7393-7400.

(25) Behrle, A. C.; Schmidt, J. A. R. Insertion Reactions and Catalytic Hydrophosphination of Heterocumulenes Using $\alpha$-Metalated N, N-Dimethylbenzylamine Rare-Earth-Metal Complexes. Organometallics 2013, 32 (5), 1141-1149.

(26) Ma, W.; Xu, L.; Zhang, W. X.; Xi, Z. Half-Sandwich Rare-Earth Metal Tris(Alkyl) Ate Complexes Catalyzed Phosphaguanylation Reaction of Phosphines with Carbodiimides: An Efficient Synthesis of Phosphaguanidines. New J. Chem. 2015, 39 (10), 7649-7655. 
(27) Batrice, R. J.; Eisen, M. S. Catalytic Insertion of E-H Bonds (E $=\mathrm{C}, \mathrm{N}, \mathrm{P}, \mathrm{S})$ into Heterocumulenes by Amido-Actinide Complexes. Chem. Sci. 2016, 7 (2), 939.

(28) Karmel, I. S. R.; Tamm, M.; Eisen, M. S. Actinide-Mediated Catalytic Addition of E-H Bonds $(\mathrm{E}=\mathrm{N}, \mathrm{P}, \mathrm{S})$ to Carbodiimides, Isocyanates, and Isothiocyanates. Angew. Chem., Int. Ed. 2015, 54 (42), 12422-12425.

(29) Itazaki, M.; Matsutani, T.; Nochida, T.; Moriuchi, T.; Nakazawa, H. Convenient Synthesis of Phosphinecarboxamide and Phosphinecarbothioamide by Hydrophosphination of Isocyanates and Isothiocyanates. Chem. Commun. 2020, 56 (3), 443-445.

(30) Härling, S.; Greiser, J.; Al-Shboul, T. M. A.; Görls, H.; Krieck, S.; Westerhausen, M. Calcium-Mediated Hydrophosphorylation of Organic Isocyanates with Diphenylphosphane Oxide. Aust. J. Chem. 2013, 66 (10), 1264-1273.

(31) Härling, S. M.; Görls, H.; Krieck, S.; Westerhausen, M. Potassium-Mediated Hydrophosphorylation of Heterocumulenes with Diarylphosphane Oxide and Sulfide. Inorg. Chem. 2016, 55 (20), 10741-10750.

(32) Härling, S. M.; Krieck, S.; Görls, H.; Westerhausen, M. Influence of 18-Crown-6 Ether Coordination on the Catalytic Activity of Potassium and Calcium Diarylphosphinites in Hydrophosphorylation Reactions. Inorg. Chem. 2017, 56 (15), 9255-9263.

(33) Bhattacharjee, J.; Harinath, A.; Banerjee, I.; Nayek, H. P.; Panda, T. K. Highly Active Dinuclear Titanium(IV) Complexes for the Catalytic Formation of a Carbon-Heteroatom Bond. Inorg. Chem. 2018, 57, 12610-12623.

(34) Boehme, C.; Wipff, G. Carbamoylphosphine Oxide Complexes of Trivalent Lanthanide Cations: Role of Counterions, Ligand Binding Mode, and Protonation Investigated by Quantum Mechanical Calculations. Inorg. Chem. 2002, 41 (4), 727.

(35) Sharova, E. V.; Artyushin, O. I.; Nelyubina, Y. V.; Lyssenko, K. A.; Passechnik, M. P.; Odinets, I. L. Complexation of N-Alkyl (Aryl)and N,N-Dialkylcarbamoylmethylphosphine Oxides with the fElements. Russ. Chem. Bull. 2008, 57 (9), 1890-1896.

(36) Ouizem, S.; Rosario-Amorin, D.; Dickie, D. A.; Paine, R. T.; de Bettencourt-Dias, A.; Hay, B. P.; Podair, J.; Delmau, L. H. Synthesis and F-Element Ligation Properties of NCMPO-Decorated Pyridine N-Oxide Platforms. Dalton Trans. 2014, 43 (22), 8368-8386.

(37) Philip Horwitz, E.; Kalina, D. C.; Diamond, H.; Vandegrift, G. F.; Schulz, W. THE TRUEX PROCESS - A PROCESS FOR THE EXTRACTION OF THE TRANSURANIC ELEMENTS FROM NITRIC ACID WASTES UTILIZING MODIFIED PUREX SOLVENT. Solvent Extr. Ion Exch. 1985, 3 (1-2), 75-109.

(38) Ozawa, M.; Koma, Y.; Nomura, K.; Tanaka, Y. Separation of Actinides and Fission Products in High-Level Liquid Wastes by the Improved TRUEX Process. J. Alloys Compd. 1998, 271-273, 538543.

(39) Kim, H.; Lee, J.; Jung, H. Study on the Carbamoyl Phosphine Oxide Moiety Functionalized Mesoporous Graphene for the Removal of Rare Earth Elements. J. Porous Mater. 2019, 26 (4), 931-939.

(40) Zarate, S. G.; Santana, A. G.; Bastida, A.; Revuelta, J. Synthetic Approaches to Heterocyclic Guanidines with Biological Activity: An Update. Curr. Org. Chem. 2014, 18 (21), 2711-2749.

(41) Zhang, W. X.; Xu, L.; Xi, Z. Recent Development of Synthetic Preparation Methods for Guanidines via Transition Metal Catalysis. Chem. Commun. 2015, 51 (2), 254-265.

(42) Ishikawa, T.; Kumamoto, T. Guanidines in Organic Synthesis. Synthesis 2006, No. 5, 737-752.

(43) Krieck, S.; Westerhausen, M. Early Main Group Metal Catalysis: Concepts and Reactions. In $\mathrm{H}-\mathrm{N}$ and H-P Bond Addition to Alkynes and Heterocumulenes; Harder, S., Ed.; Wiley: Hoboken, NJ, 2020; pp 123-150.

(44) Gawande, M. B.; Bonifácio, V. D. B.; Luque, R.; Branco, P. S.; Varma, R. S. Solvent-Free and Catalysts-Free Chemistry: A Benign Pathway to Sustainability. ChemSusChem 2014, 7 (1), 24-44.

(45) Parodi, F. Isocyanate-Derived Polymers. Comprehensive Polymer Science and Supplements; Elsevier: Amsterdam, Netherlands, 1989; Vol. 5, Chapter 23, pp 387-412.
(46) Moglie, Y.; González-Soria, M. J.; Martín-García, I.; Radivoy, G.; Alonso, F. Catalyst- and Solvent-Free Hydrophosphination and Multicomponent Hydrothiophosphination of Alkenes and Alkynes. Green Chem. 2016, 18 (18), 4896-4907.

(47) Alonso, F.; Moglie, Y.; Radivoy, G.; Yus, M. Solvent- and Catalyst-Free Regioselective Hydrophosphanation of Alkenes. Green Chem. 2012, 14 (10), 2699-2702.

(48) Wen, L. R.; Sun, Y. X.; Zhang, J. W.; Guo, W. S.; Li, M. Catalyst- and Solvent-Free Bisphosphinylation of Isothiocyanates: A Practical Method for the Synthesis of Bisphosphinoylaminomethanes. Green Chem. 2018, 20 (1), 125-129.

(49) Kaboudin, B.; Zahedi, H. A Noval and Convenient Method for Synthesis of Carbamoyl and Thiocarbamoyl Phosphonates. Heteroat. Chem. 2009, 20 (4), 250-253.

(50) Karol, M. H.; Jin, R. Mechanisms of Immunotoxicity to Isocyanates. Chem. Res. Toxicol. 1991, 4 (5), 503-509.

(51) Nakashima, K.; Takeshita, T.; Morimoto, K. Review of the Occupational Exposure to Isocyanates: Mechanisms of Action. Environ. Health Prev. Med. 2002, 7 (1), 1-6.

(52) Aguiar, A. M.; Giacin, J.; Greenberg, H. J. Reaction of Lithium Diphenylphosphide and Carbonyl Compounds. J. Org. Chem. 1963, 28 (12), 3545-3547.

(53) Morgalyuk, V. P.; Strelkova, T. V.; Nifant'Ev, E. E. Ambident Reactivity of Chloro(Dialkylamino)-(Diphenylphosphinoyl)Methanes. Bull. Chem. Soc. Jpn. 2012, 85 (1), 93-100.

(54) Bigi, F.; Maggi, R.; Sartori, G. Selected Syntheses of Ureas through Phosgene Substitutes. Green Chem. 2000, 2 (4), 140-148.

(55) Kreye, O.; Mutlu, H.; Meier, M. A. R. Sustainable Routes to Polyurethane Precursors. Green Chem. 2013, 15 (6), 1431-1455.

(56) Carnaroglio, D.; Martina, K.; Palmisano, G.; Penoni, A.; Domini, C.; Cravotto, G. One-Pot Sequential Synthesis of Isocyanates and Urea Derivatives via a Microwave-Assisted Staudinger-Aza-Wittig Reaction. Beilstein J. Org. Chem. 2013, 9, 2378-2386.

(57) Wang, P.; Liu, S.; Deng, Y. Important Green Chemistry and Catalysis: Non-Phosgene Syntheses of Isocyanates - Thermal Cracking Way. Chin. J. Chem. 2017, 35 (6), 821-835.

(58) Chamni, S.; Zhang, J.; Zou, H. Benign Synthesis of Unsymmetrical Arylurea Derivatives Using 3-Substituted Dioxazolones as Isocyanate Surrogates. Green Chem. Lett. Rev. 2020, 13 (3), $246-257$.

(59) Geeson, M. B.; Cummins, C. C. Let's Make White Phosphorus Obsolete. ACS Cent. Sci. 2020, 6, 848-860.

(60) Geeson, M. B.; Cummins, C. C. Phosphoric acid as a precursor to chemicals traditionally synthesized from white phosphorus. Science 2018, 359, 1383-1385.

(61) Montchamp, J.-L. Phosphinate Chemistry in the 21st Century: A Viable Alternative to the Use of Phosphorus Trichloride in Organophosphorus Synthesis. Acc. Chem. Res. 2014, 47 (1), 77-87.

(62) Baslé, O.; Li, C. J. Copper-Catalyzed Aerobic Phosphonation of $\mathrm{sp}^{3}$ C-H Bonds. Chem. Commun. 2009, 4124-4126.

(63) Han, W.; Mayer, P.; Ofial, A. R. Iron-Catalyzed Oxidative Mono- And Bis-Phosphonation of N,N-Dialkylanilines. Adv. Synth. Catal. 2010, 352 (10), 1667-1676.

(64) Xie, J.; Li, H.; Xue, Q.; Cheng, Y.; Zhu, C. A Scalable, Efficient Gold-Catalyzed Oxidative Phosphonation of $\mathrm{sp}^{3} \mathrm{C}-\mathrm{H}$ Bonds Using Air as Sustainable Oxidant. Adv. Synth. Catal. 2012, 354 (9), 16461650.

(65) Ortial, S.; Fisher, H. C.; Montchamp, J. L. Hydrophosphinylation of Unactivated Terminal Alkenes Catalyzed by Nickel Chloride. J. Org. Chem. 2013, 78 (13), 6599-6608.

(66) Arnold, R. G.; Nelson, J. A.; Verbanc, J. J. Recent Advances in Isocyanate Chemistry. Chem. Rev. 1957, 57 (1), 47-76. 